\title{
Influence of Precursor Temperature on Bi Doped ZnSe Material via Electrochemical Deposition Technique for Photovoltaic Application
}

\author{
Imosobomeh L. Ikhioya $^{\text {a }}$, Eli Danladi ${ }^{\text {b,*, }}$, Okoli D. Nnanyere ${ }^{c}$, Abdulazeez O. Salawu ${ }^{\mathrm{d}}$ \\ ${ }^{a}$ Department of Physics and Astronomy, Faculty of Physical Sciences, University of Nigeria, Nsukka, Enugu State, Nigeria \\ ${ }^{b}$ Department of Physics, Faculty of Science, Federal University of Health Sciences, Otukpo, Benue State, Nigeria \\ ${ }^{c}$ Department of Physics and Industrial Physics, Faculty of Physical Sciences, Nnamdi Azikiwe University, Awka, Anambra State, Nigeria \\ ${ }^{d}$ Department of Computer Science, Nile University of Nigeria
}

\begin{abstract}
In this study, Bismuth (Bi) doped $\mathrm{ZnSe}$ thin films were deposited on conducting glass substrates by electrochemical deposition technique and the influence of precursor temperature (room, 50,55, $60^{\circ} \mathrm{C}$ ) on their optical and structural properties were systematically studied using the combined effect of X-Ray Diffraction (XRD), Scanning Electron Microscope (SEM) and UV-VIS spectrophotometer. The XRD patterns show a face-centred cubic structure indexed with peaks at (220), (221) and (300). The grain size was in the range of 3.24056 to $4.60481 \mathrm{~nm}$ with a lattice constant of $7.189 \AA$. The material deposited at room, $50^{\circ} \mathrm{C}, 55^{\circ} \mathrm{C}$, and $60^{\circ} \mathrm{C}$ reveals agglomeration of particle on the surface of the substrate indicating uniform deposition. The optical spectra show that at different temperature (say room, $50^{\circ} \mathrm{C}, 55^{\circ} \mathrm{C}$ and $60^{\circ} \mathrm{C}$ ), the absorbance and reflectance of $\mathrm{BiZnSe}$ thin films decreases with increase in wavelength of the incident radiation while the transmittance shows direct proportionality with the increase in wavelength. The bandgap demonstrated an increase in the range 1.75-2.25 eV with increase in temperature.
\end{abstract}

\section{DOI:10.46481/jnsps.2022.502}

Keywords: ZnSe, Doping, Precursor temperature, Photovoltanic, Electrochemical deposition

Article History :

Received: 05 December 2021

Received in revised form: 03 February 2022

Accepted for publication: 15 February 2022

Published: 28 February 2022

(C)2022 Journal of the Nigerian Society of Physical Sciences. All rights reserved. Communicated by: E. Etim

\section{Introduction}

Among the various II-VI semiconductors, Zinc selenide displays unique optical properties that makes it found application in light-emitting diodes [1,2], magneto-optical devices [3], ultraviolet lasers [4,5], gas sensors [6,7], solar cells [8,9], photocatalysis to mention but a few. The band gap tunability of $\mathrm{ZnSe}$ makes its optical properties outstanding and it can be used as

\footnotetext{
${ }^{*}$ Corresponding author tel. no: +2348063307256

Email address: danladielibako@gmail .com (Eli Danladi )
}

transparent conductive oxide thin films. Many methods, both chemical and physical, including sputtering [10], thermal evaporation [11], electro-deposition [12, 20, 21], spray pyrolysis [13] and chemical vapour deposition [14] have been used to produce doped and undoped semiconductor thin films. So far, some of the methods have drawbacks such as toxic reducing agents, and organic solvents, or may require special conditions such as high temperature or low pressure, and sometimes can require costly and time consuming procedure.

Among them, the electrochemical deposition of thin films is a viable alternative to vacuum-based deposition process. Its 


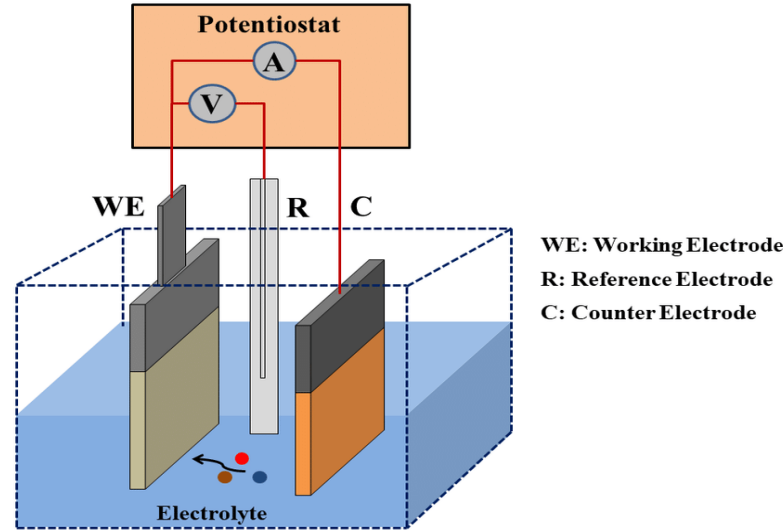

Figure 1: Schematic diagram of electrochemical deposition technique

major advantages are that processing can take place at room temperatures and pressures and thin film properties can be controlled $[4,10]$.

Generally speaking, adding an appropriate amount of dopant can change the physical properties of a semiconductor film. The effects of sulfur (S), iron (Fe), chromium (Cr) [15], copper $(\mathrm{Cu})$ [16], Ag [17], Mn [18], etc. have been systematically studied. The semi-metal element bismuth (Bi) is used as a suitable doping material for electronic applications because of its high anisotropic electrical properties and high electron mobility $[10,19]$, which is rarely reported in published works. Bidoped $\mathrm{ZnSe}$ thin film has a transparent nature, and its band gap nature results to potential support for heterojunction layers in solar cells. This work aims to use X-ray diffraction (XRD), scanning electron microscopy (SEM), Energy Dispersive Spectroscopy (EDS), ultraviolet-visible absorption spectroscopy and four point probe to explore the structural, optical and electrical properties of the as-deposited thin film.

\section{Experimental Details}

\subsection{Material and Methods}

The chemicals used in this work were analytical grade and purchased from Sigma-Aldrich. They include: zinc tetraoxosulphate (VI) heptahydrate $\left(\mathrm{ZnSO}_{4} .7 \mathrm{H}_{2} \mathrm{O}\right)$, Bismuth nitrate pentahydrate $\left(\mathrm{Bi}\left(\mathrm{NO}_{2}\right)_{3} .5 \mathrm{H}_{2} \mathrm{O}\right)$, selenium metal powder $(\mathrm{Se})$, and hydrogen chloride $(\mathrm{HCl})$. In this work, electrochemical deposition technique (ECD) is used, which involves the deposition of any substance on electrodes due to electrolysis. The electrochemical bath system consists of cation source (ie $\mathrm{Bi}\left(\mathrm{NO}_{2}\right)_{3} .5 \mathrm{H}_{2} \mathrm{O}$ $\mathrm{ZnSO}_{4} .7 \mathrm{H}_{2} \mathrm{O}$ for $\mathrm{Bi}^{2+}, \mathrm{Zn}^{2+}$ ), anion source (i.e. selenium metal powder $\mathrm{Se}^{2-}$ ) and deionized water, all in a $100 \mathrm{ml}$ beaker. The reaction bath was stirred using a magnetic stirrer, and a powder supplied was used to supply an electric field (DC voltage), a conductive glass (FTO) with electrical resistance of $16.6 \Omega$ for the cathode, and a carbon electrode for the anode. Finally, the uniform deposition of the thin film was achieved through electrochemical deposition technique.

\subsection{Substrate Cleaning Procedure}

The substrates were conducting glass materials. Acetone was used to cleaned the substrates. It was therefore rinsed with distilled water and ultrasonicated for 30 minutes in acetone solution. Final rinsing was done in distilled water and the substrates were dried using an oven.

\subsection{Growth of ZnSe and Bi/ZnSe Films}

The growth of $\mathrm{ZnSe}$ and $\mathrm{Bi} / \mathrm{ZnSe}$ thin film materials was carried out using an aqueous solution of $0.1 \mathrm{~mol}$ of $\mathrm{ZnSO}_{4} \cdot 7 \mathrm{H}_{2} \mathrm{O}$ as the cationic precursor while the anionic precursor was 0.1 mol solution of selenium metal powder dissolved in $5 \mathrm{ml}$ of hydrochloric acid $(\mathrm{HCl})$ to ensure uniform deposition. The electrochemical bath system was composed of sequential variations of the zinc selenide molar concentrations. The varied precursor temperature of the solution are presented in Table 1. The deposited films were afterward annealed at $300{ }^{\circ} \mathrm{C}$.

\subsection{Characterization and Measurement}

The grown films were characterized for their morphological, structural, elemental, optical and electrical properties using Zeiss scanning electron microscope (SEM), Bruker D8 Advance $\mathrm{X}$-ray diffractometer with $\mathrm{Cu}-\mathrm{K}_{\alpha}$ line $(\lambda=1.5405 \AA)$ in $2 \theta$ range from $10^{\circ}-90^{\circ}$, energy dispersive $\mathrm{X}$-ray spectroscope (EDX), Uv-1800 visible spectrophotometer and a fourpoint probe device respectively.

\section{Results and Discussion}

\subsection{XRD analysis}

The XRD pattern of BiZnSe thin films deposited on FTO substrates at different temperatures is as shown in Figure 2. From the Figure, the diffraction peaks were at (220), (221), (300) which correspond to the following angles $\left(26.00^{\circ}\right),\left(31.98^{\circ}\right)$, $\left(32.01^{\circ}\right)$ respectively. From the pattern, BiZnSe was confirmed to be a face-centred cubic structure which agrees with the JCPDS card no. 01-088-2400. The un-indexed peaks could have possibly resulted from the FTO substrates used for deposition. The lattice constant $\mathrm{a}=7.1890 \AA$ was obtained using equation (1). From the pattern the higher peaks could be due to the fact that the thickness of the film increases with an increase in dopant concentration, thus creating larger surface areas for photovoltaic devices and solar cell activities. The average crystallite size of the film is determined using equation (1), and the value of the Scherrer constant $\mathrm{K}$ is estimated to be 0.94 of the crystallite size using equation (2). Table 2 shows the calculated crystallite or grain size and dislocation density of the films deposited at different temperature room, $50^{\circ} \mathrm{C}, 55^{\circ} \mathrm{C}$ and $60^{\circ} \mathrm{C}$ which agrees to similar studies by other researchers [20-23].

$$
\begin{aligned}
& d=\frac{n \lambda}{2 \sin \theta} \\
& D=\frac{k \lambda}{B \cos \theta}
\end{aligned}
$$


Table 1: Varied molar concentration of growth materials

\begin{tabular}{ccccccc}
\hline Temperature (degree) & $\mathbf{B i}\left(\mathbf{N O}_{2}\right)_{3} . \mathbf{5 H}_{2} \mathbf{O}(\mathbf{m l})$ & $\mathbf{Z n S O}_{\mathbf{4}} \mathbf{. 7} \mathbf{H}_{\mathbf{2}} \mathbf{O}(\mathbf{m l})$ & $\mathbf{S e}(\mathbf{m l})$ & Temperature (degree) & Time (s) & Voltage $(\mathbf{V})$ \\
\hline $\mathrm{ZnSe}$ & 10 & 20 & 20 & 00 & 5 & 10 \\
$\mathrm{Bi} / \mathrm{ZnSe} 50$ & 10 & 20 & 20 & 50 & 5 & 10 \\
$\mathrm{Bi} / \mathrm{ZnSe} 55$ & 10 & 20 & 20 & 55 & 5 & 10 \\
$\mathrm{Bi} / \mathrm{ZnSe}$ 60 & 10 & 20 & 20 & 60 & 5 & 10 \\
\hline
\end{tabular}

Table 2: Structural parameters of BiZnSe thin film

\begin{tabular}{|c|c|c|c|c|c|c|c|}
\hline Sample & $\begin{array}{l}\mathbf{2 \theta} \\
\text { (degree) }\end{array}$ & $\begin{array}{l}\text { d (spac- } \\
\text { ing) } \\
\AA\end{array}$ & $\begin{array}{l}\text { Lattice } \\
\text { constant } \\
\text { (̊) }\end{array}$ & $\begin{array}{l}\text { (及) } \\
\text { FWHM }\end{array}$ & (hkl) & $\begin{array}{l}\text { Grain } \\
\text { Size(D) } \\
\text { nm }\end{array}$ & $\begin{array}{l}\text { Dislocation } \\
\text { density, } \sigma \\
\text { lines } / \mathbf{m}^{2}\end{array}$ \\
\hline \multirow[t]{3}{*}{ ZnSe room } & 27.07 & 3.52076 & 7.1890 & 0.32717 & 220 & 4.54275 & 0.04845 \\
\hline & 38.98 & 2.87509 & & 0.32717 & 221 & 4.60447 & 0.04716 \\
\hline & 51.01 & 2.87246 & & 0.32717 & 300 & 4.60481 & 0.04716 \\
\hline \multirow{3}{*}{$\begin{array}{l}\text { Bi/ZnSe } \\
5^{0} \mathrm{C}\end{array}$} & 27.07 & 3.52076 & 7.1890 & 0.40959 & 220 & 3.62863 & 0.07594 \\
\hline & 38.98 & 2.87509 & & 0.40959 & 221 & 3.67793 & 0.07392 \\
\hline & 51.01 & 2.87246 & & 0.40959 & 300 & 3.67820 & 0.07391 \\
\hline \multirow{3}{*}{$\begin{array}{l}\text { Bi/ZnSe } \\
55^{0} \mathrm{C}\end{array}$} & 27.07 & 3.52076 & 7.1890 & 0.45864 & 220 & 3.24056 & 0.09522 \\
\hline & 38.98 & 2.87509 & & 0.45864 & 221 & 3.28459 & 0.09269 \\
\hline & 51.01 & 2.87246 & & 0.45864 & 300 & 3.28483 & 0.09267 \\
\hline \multirow{3}{*}{$\begin{array}{l}\mathrm{Bi} / \mathrm{ZnSe} \\
\mathbf{6 0}^{0} \mathrm{C}\end{array}$} & 27.07 & 3.52076 & 7.1890 & 0.36444 & 220 & 4.07818 & 0.06012 \\
\hline & 38.98 & 2.87509 & & 0.36444 & 221 & 4.13358 & 0.05852 \\
\hline & 51.01 & 2.87246 & & 0.36444 & 300 & 4.13389 & 0.05851 \\
\hline
\end{tabular}

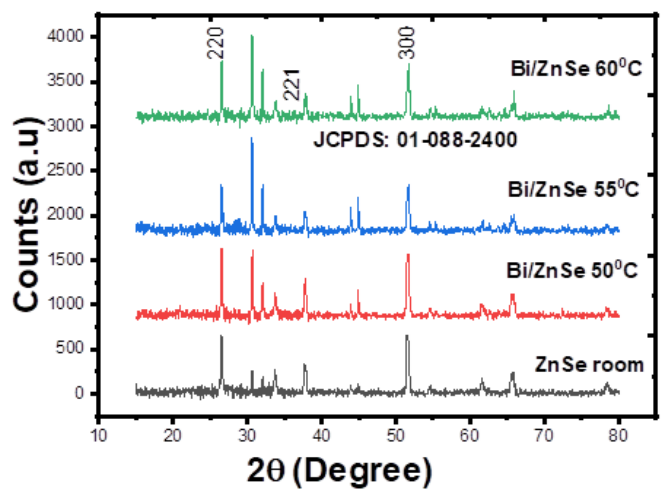

Figure 2: XRD pattern of BiZnSe

\subsection{Surface Morphology Analysis Using Scanning Electron Mi- croscopy (SEM) of BiZnSe}

Figure 3 shows the micrograph of $\mathrm{ZnSe}$ and $\mathrm{BiZnSe}$. The materials were deposited at room, $50^{\circ} \mathrm{C}, 55^{\circ} \mathrm{C}$, and $60^{\circ} \mathrm{C}$. The morphologies of the samples at different temperatures are smooth with bigger grains with decrease in temperature. When the deposition temperature increased to $60^{\circ} \mathrm{C}$ the surface of the as deposited film resulted to formation of islands with reduced grains due to smaller crystallites formed. The large grains formed with reduced precursor temperature was due to agglomeration of the crystallites. It is evidenced that the crystallites get bigger as the deposition temperature reduces which agrees with similar studies [20-23].

\subsection{Elemental Composition Analysis Using Energy Dispersive $X$-ray (EDX) for BiZnSe}

Utilizing Energy Dispersive X-ray technique, the formation of $\mathrm{ZnSe}$ and BiZnSe are evident in Figure $4 \mathrm{a} \& \mathrm{~b}$ and the other elements which include $\mathrm{Si}, \mathrm{Ca}$, and $\mathrm{O}$ resulted from the elemental composition of the (FTO) substrate used for the deposition of the films.

\subsection{Optical Analysis}

The optical absorbance-wavelength spectra of BiZnSe thin films is shown in Figure 5a. The films grown at different temperatures (say, room, $50^{\circ} \mathrm{C}, 55^{\circ} \mathrm{C}$ and $60^{\circ} \mathrm{C}$ ) reveals that, the absorbance has an inverse relationship with its corresponding wavelength (in another word, as the wavelength of the incident radiation increases the absorbance of BiZnSe thin films decreases). The material grown at $50^{\circ} \mathrm{C}, 55^{\circ} \mathrm{C}$ and $60^{\circ} \mathrm{C}$ exhibited the same trend and reveals the highest behavior and the material grown at room reveals lowest which shows that $\mathrm{ZnSe}$ and BiZnSe will be a good material that will absorb energy from the Sun and can serve as a good device for photovoltaic applications [24-26].

The optical transmittance spectra of BiZnSe thin films in Figure $5 \mathrm{~b}$ shows that the transmittance of the films grown at 

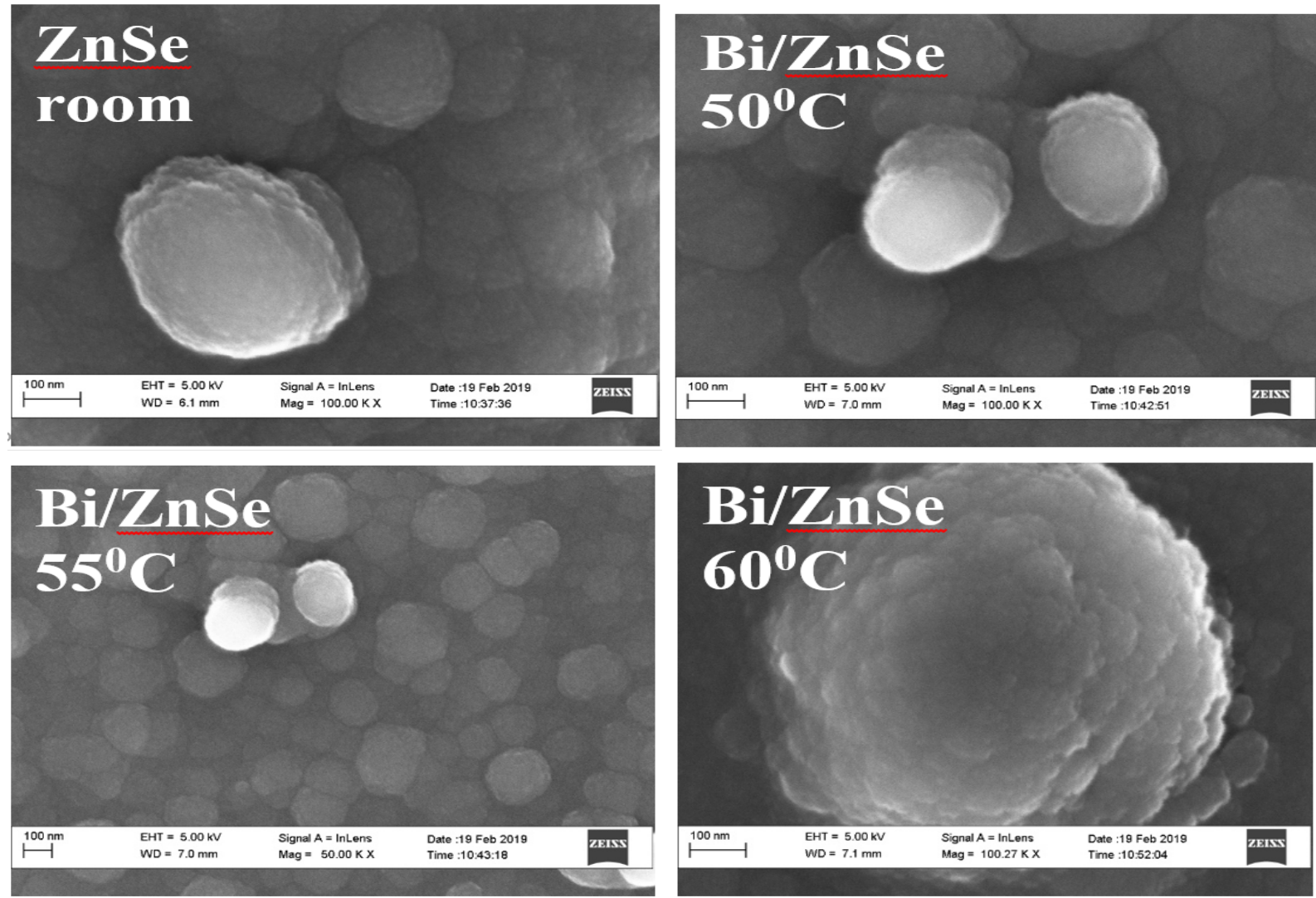

Figure 3: SEM Micrograph of $\mathrm{ZnSe}$ and BiZnSe
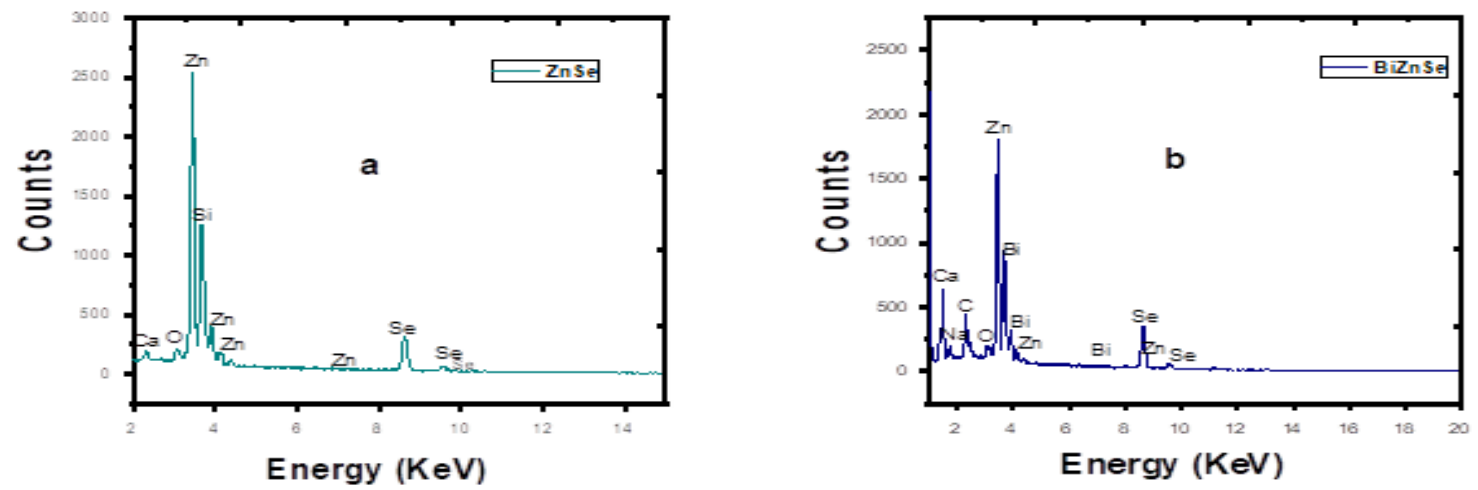

Figure 4: EDX Spectra of ZnSe and BiZnSe

different temperatures (room, $50^{\circ} \mathrm{C}, 55^{\circ} \mathrm{C}$ and $60^{\circ} \mathrm{C}$ ) increases with increased in wavelength, which means that, the transmittance is directly related with the wavelength of BiZnSe thin films which agrees with similar studies [24-26].

Similarly, the optical reflectance spectra of BiZnSe thin films in Figure 5c shows an inverse relationship with wavelength which means that, at different temperatures (room, $50^{\circ} \mathrm{C}, 55^{\circ} \mathrm{C}$ and $60^{\circ} \mathrm{C}$ ) as the wavelength of the incident radiation increase the reflectance of BiZnSe thin films decreases.

The energy gap $\left(\mathrm{E}_{g}\right)$ was determined based on the wavelength of maximum absorption $(\lambda)$ according to the formula $\mathrm{E}_{g}$
$=1240 / \lambda$. Here, the maximum absorption wavelength is obtained from the absorption wavelength data. The $\mathrm{E}_{g}$ was obtained in the formula describes as Tauc plot [27]. The $\mathrm{E}_{g}$ was obtained from extrapolation of the linear part $(\alpha \mathrm{h} v)^{2}$ versus $\mathrm{h} v$.

The optical band gap energy of BiZnSe thin films in Figure 6 shows an increase in band gap energy with increase in deposition temperature. The bandgap demonstrated an increase in the range $1.75-2.25 \mathrm{eV}$ with increase in temperature (room, $50^{\circ} \mathrm{C}$, $55^{\circ} \mathrm{C}$ and $\left.60^{\circ} \mathrm{C}\right)$.

Figure 7a shows the optical refractive index of BiZnSe thin films grown at different temperature (room, $50^{\circ} \mathrm{C}, 55^{\circ} \mathrm{C}$ and 

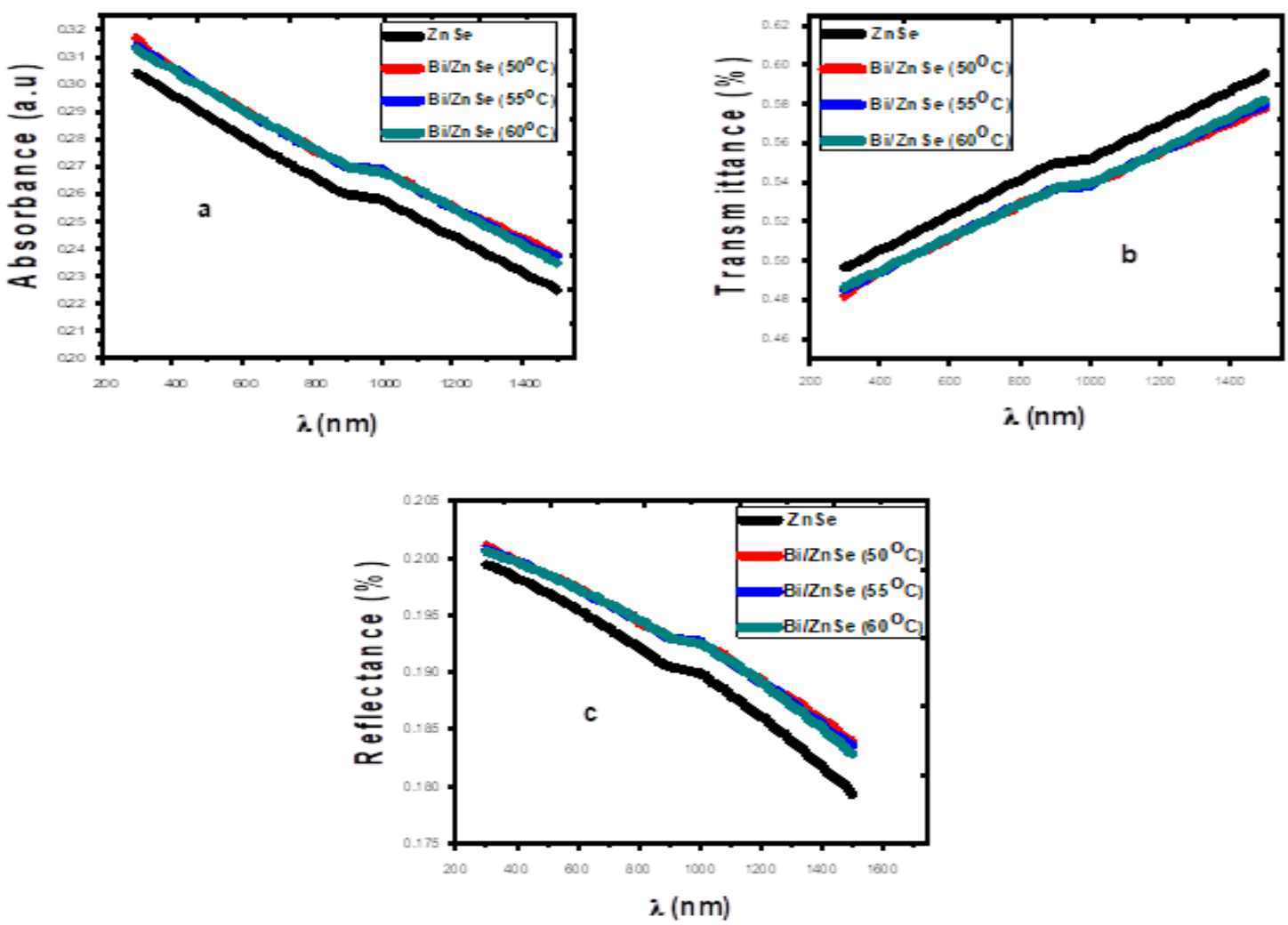

Figure 5: Absorbance (a), transmittance (b) and reflectance (c) versus wavelength

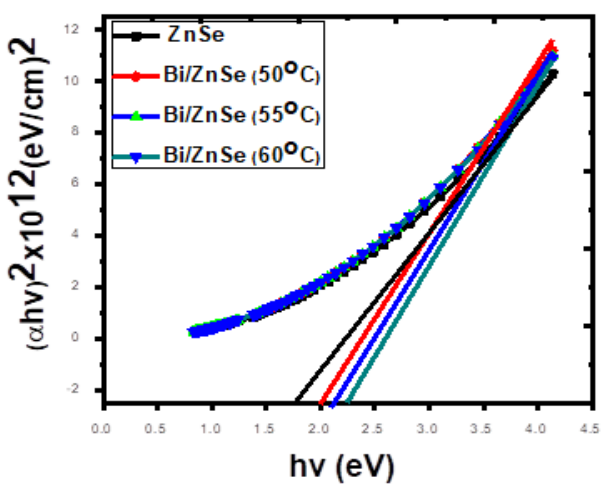

Figure 6: Plot of absorption coefficient square versus photon energy

$\left.60^{\circ} \mathrm{C}\right)$. The result shows that, as the photon energy of the material increases the refractive index also increases. The increase in the refractive index as a result of photon energy increase was due to larger crystallites as observed in the SEM micrograph while the refractive index increases with increasing photon energy as a result of the increase in grain size observed in the SEM analysis. The refractive index $(\mathrm{n})$ is the range of frequencies in which films are weakly absorbing.

The optical extinction coefficient which is the measure of the fraction of light lost due to scattering and absorption per unit distance of the penetration medium is as shown in Figure $7 \mathrm{~b}$. The increase in the extinction coefficient indicates the scattering loss of light while travelling through the medium with high absorption. The optical conductivity of BiZnSe thin films is shown in Figure 7c. The optical conductivity has been found to increase with increase photon energy. This increase in optical conductivity attributed to increase in density of localized states in the energy band itself is due to the rise in new defect states [28].

The real and imaginary dielectric constant of BiZnSe thin films in figure $8 \mathrm{a} \& \mathrm{~b}$ has a direct relationship with the photon energy. This shows that, as the photon energy of the material increases, the real and imaginary dielectric constants increases.

\subsection{Electrical Properties of BiZnSe}

The material deposited at room, $50^{\circ} \mathrm{C}, 55^{\circ} \mathrm{C}$ and $60^{\circ} \mathrm{C}$ reveals an increase in thickness from $117.19-132.21 \mathrm{~nm}$ with increase in the resistivity of the deposited material from $5.3210 \times$ $10^{3}--6.2943 \times 10^{3}(\Omega . \mathrm{cm})$ which result to the decrease in the conductivity of the deposited material from $1.8793 \times 10^{11}$ $1.5887 \times 10^{11}(\mathrm{~S} / \mathrm{m})($ See Figure 9$)$.

The high resistance value allows the film to be used in solar cell applications to improve conversion efficiency, because it can reduce the inevitable defects in solar cell manufacturing during the actual production process. Therefore, BiZnSe thin 

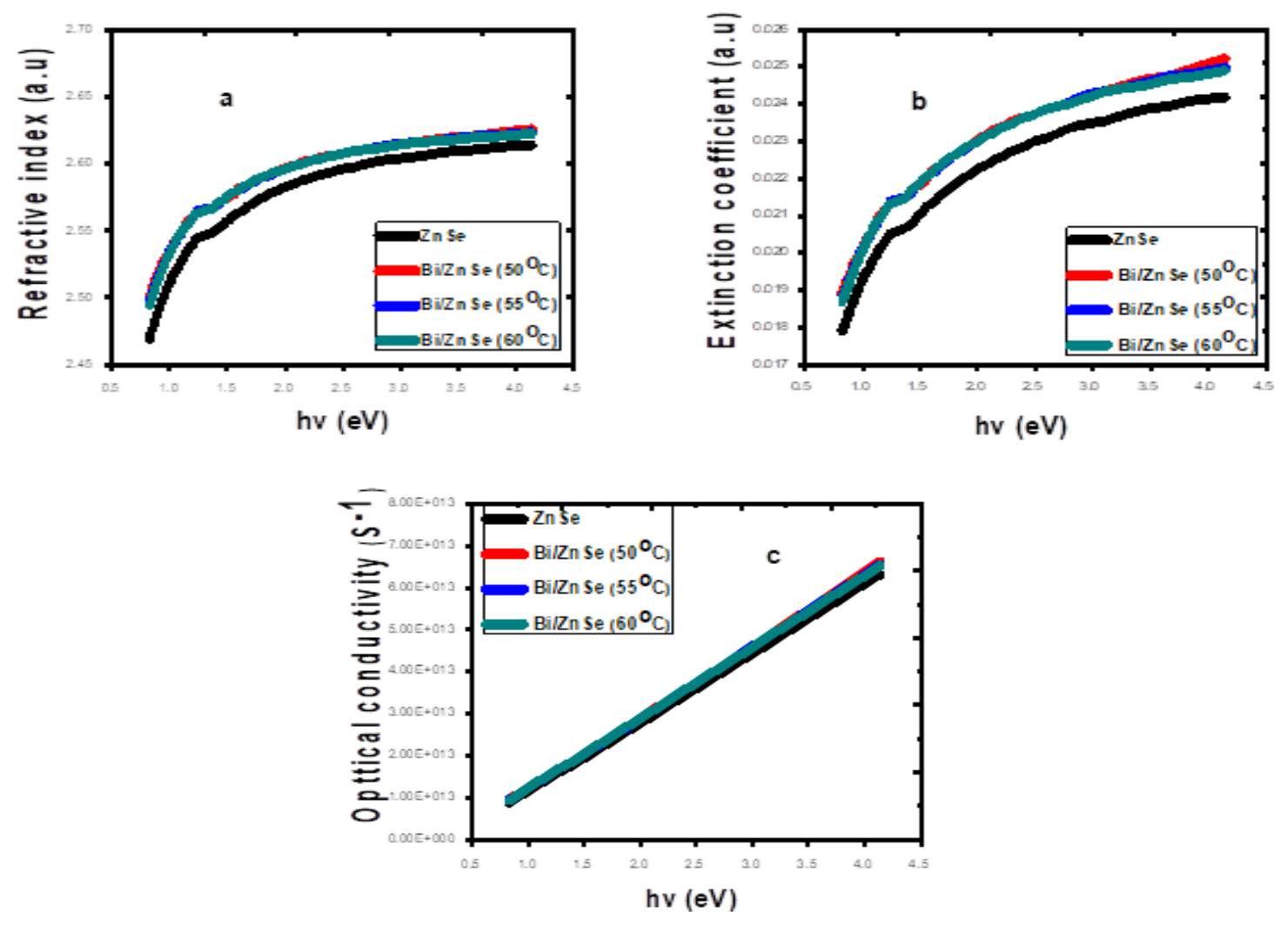

Figure 7: Refractive index (a), extinction coefficient (b) and optical conductivity (c) versus photon energy
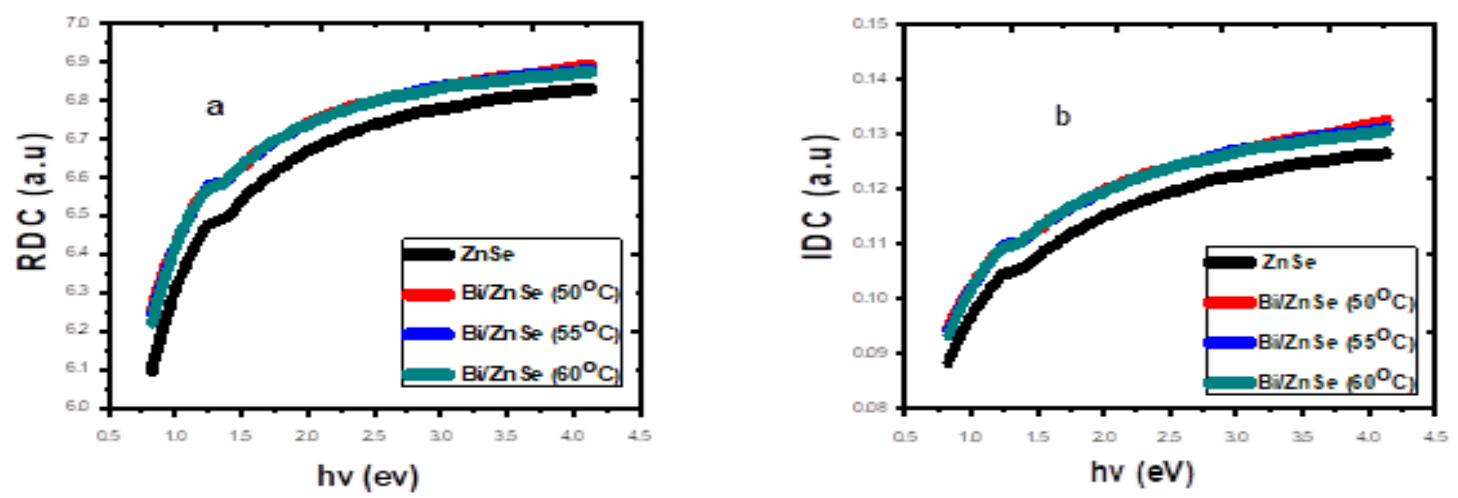

Figure 8: Plot of real dielectric (a) imaginary dielectric constant (b) versus photon energy

Table 3: Electrical Properties of BiZnSe

\begin{tabular}{cccc}
\hline Samples & Thickness, t(nm) & Resistivity, $\boldsymbol{\rho}(\Omega . \mathrm{cm})$ & Conductivity, $\boldsymbol{\sigma}(\mathrm{S} / \mathrm{m})$ \\
\hline $\mathrm{ZnSe}$ room & 117.19 & $5.3210 \times 10^{3}$ & $1.8793 \times 10^{11}$ \\
$\mathrm{Bi} / \mathrm{ZnSe} 50^{\circ} \mathrm{C}$ & 122.15 & $6.7231 \times 10^{3}$ & $1.4874 \times 10^{11}$ \\
$\mathrm{Bi} / \mathrm{ZnSe} 55^{\circ} \mathrm{C}$ & 128.15 & $6.9874 \times 10^{3}$ & $1.4311 \times 10^{11}$ \\
$\mathrm{Bi} / \mathrm{ZnSe} 60^{\circ} \mathrm{C}$ & 132.21 & $6.2943 \times 10^{3}$ & $1.5887 \times 10^{11}$ \\
\hline
\end{tabular}

film resistivity is very suitable for use as a buffer layer in solar cells, photovoltaic panels and photovoltaic devices.

\section{Conclusion}

Undoped $\mathrm{ZnSe}$ and Bismuth (Bi) doped $\mathrm{ZnSe}$ thin films have been prepared and deposited using electrochemical de- 


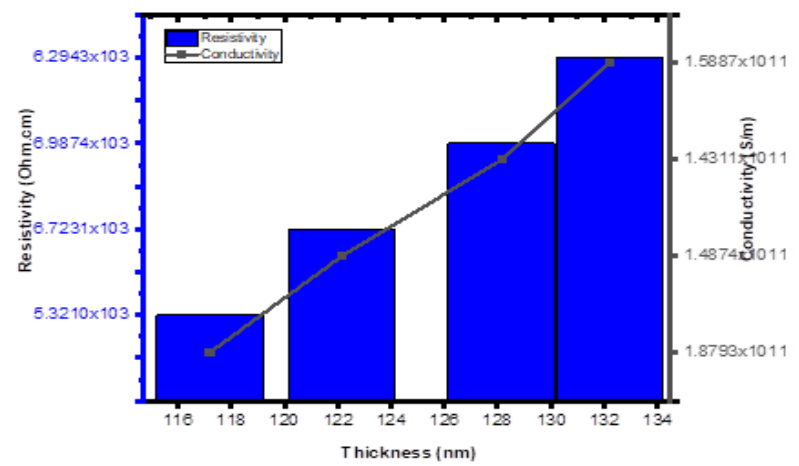

Figure 9: Resistivity and conductivity versus thickness

position technique at room, $50,55,60{ }^{\circ} \mathrm{C}$. The XRD patterns show a face-centred cubic structure indexed with peaks at (220), (221) and (300). The grain size was in the range of 3.24056 to $4.60481 \mathrm{~nm}$ with a lattice constant of $7.189 \AA$. The material deposited at room, $50^{\circ} \mathrm{C}, 55^{\circ} \mathrm{C}$, and $60^{\circ} \mathrm{C}$ reveals agglomeration of particle on the surface of the substrate indicating uniform deposition. The optical spectra show that at different temperature (say room, $50^{\circ} \mathrm{C}, 55^{\circ} \mathrm{C}$ and $60^{\circ} \mathrm{C}$ ), the absorbance and reflectance of BiZnSe thin films decreases with increase in wavelength of the incident radiation while the transmittance shows direct proportionality with the increase in wavelength. The bandgap demonstrated an increase in the range 1.75-2.25 eV with increase in temperature.

\section{Acknowledgements}

We acknowledge Nanosciences African Network (NANOAFNET), iThemba LABS National Research Foundation as well as the staff of Nano Research Group, University of Nigeria, Nsukka for their research support

\section{References}

[1] S. J. Pearton \& F. Ren, "Advances in ZnO-based materials for light emitting diodes", Current Opinion in Chemical Engineering 3 (2014) 51.

[2] H. Dae-Kue, O. Min-Suk, L. Jae-Hong \& P. Seong-Ju, "ZnOthinfilms and light-emitting diodes", Journal of Physics D: Applied Physics 40 (2007) R387.

[3] K. Ando, H. Saito, Z. Jin, T. Fukumura, M. Kawasaki, Y. Matsumoto \& H. Koinuma, "Large magneto-optical effect in an oxide diluted magnetic semiconductor Zn1-xCoxO", Applied Physics Letters 78, (2001) 2700.

[4] M. H. Huang, S. Mao, H. Feick, H. Q. Yan, Y. Y. Wu, H. Kind, E. Weber, R. Russo \& P. D. Yang, "Room-temperature ultraviolet nanowire nanolasers", Science 292 (2001) 1897.

[5] K. Govender, D. S. Boyle, P. O’Brien, D. Binks, D. West \& D. Coleman, "Room temperature lasing observed from $\mathrm{ZnO}$ nanocolumns grown by aqueous solution deposition", Advanced Materials 14 (2002) 1221.

[6] L. Wang, Y. Kang, X. Liu, S. Zhang, W. Huang \& S. Wang, "ZnO nanorod gas sensor for ethanol detection", Sensors and Actuators B: Chemical 162 (2012) 237

[7] P. H. Yeh, Z. Li \& Z. L. Wang, "Schottky-gated probe-free ZnO nanowire biosensor", Advanced Materials 21 (2009) 4975.
[8] J. Huang, Z. Yin \& Q. Zheng, "Applications of $\mathrm{ZnO}$ in organic and hybrid solar cells, Energy and Environmental Science 4 (2001) 3861.

[9] B. Weintraub, Y. G. Wei \& Z. L. Wang, "Optical fiber/nanowire hybrid structures for efficient three-dimensional dye-sensitized solar cells", Angewandte Chemie 48 (2009) 8981.

[10] A. Kennedy, V. S. Kumar \& K. P. Raj, "Influence of substrate temperature on structural, morphological, optical and electrical properties of Bi-doped $\mathrm{MnInS}_{4}$ thin films prepared by nebuliser spray pyrolysis technique", Journal of Physics and Chemistry of Solids 110 (2017) 100.

[11] R. Inov \& D. Desheva, "Preparation and characterization of amorphous $\mathrm{SeTe} / \mathrm{CdSe}$ superlattices and their constituent thin layers", Thin Solid Films 213 (1992) 230.

[12] R. P. Raffaelle, H. Forsell, T. Potdevis, R. Fridefeld, J. G. Mortovani, S. G. Bailey, S.M. Hubbard, E.M. Gordon \& A.F. Hepp, "Elecrodeposited CdS on CIS pn junction", Solar Energy Materials and Solar Cells 57 (1999) 167.

[13] K. Subbaramaiah \& V. S. Raja, "Preparation and characterization of all spray-deposited $p-C u \ln \left(S_{0,5} S e_{0,5}\right)_{2} / n-C d Z n S$ : In thin film solar cells" Solal Energy Materials and Solar Cells 32 (1994) 1.

[14] S. Tec-Yam, R. Potino \& A. I. Oliva, "Chemical bath deposition of CdS films on different substrate orientations", Current Applied Physics 11 (2011) 914.

[15] N. B. Singh, C. H. Su, F. S. Choa, B. Arnold, P. Gill, C. Su, I. Emge \& R. Sood, "Effect of Doping on the Electrical Characteristics of ZnSe", Crystals 10 (2020) 551.

[16] M. M. Rahman, C. Das, M. M. Rahaman, K. M. A. Hussain \& S. Choudhury, "Effect of thickness on structural, morphological and optical properties of copper $(\mathrm{Cu})$ doped zinc selenide $(\mathrm{ZnSe})$ thin filmd by vacuum evaporation method", Bangladesh Academy of Science 43 (2019) 159.

[17] K. Yadav \& N. Jaggi, "Effect of Ag doping on structural and optical properties of ZnSe nanophosphors", Materials Science in Semiconductor Processing 30 (2015) 376

[18] F. Qiao, R. Kang, Q. Liang, Y. Cai, J. Bian \& X. Hou, "Tunability in the Optical and Electronic Properties of $\mathrm{ZnSe}$ Microspheres via $\mathrm{Ag}$ and $\mathrm{Mn}$ Doping", ACS Omega 4 (2019) 12271.

[19] M. Mrad, B. Chouchene \& T. B. Chaabane "Effects of Zinc Precursor, Basicity and Temperature on the Aqueous Synthesis of ZnO Nanocrystals" South African Journal of Chemistry 71 (2018) 103.

[20] K. Yadav Y. Dwivedi \& N. Jaggi, "Structural and optical properties of Ni doped ZnSe nanoparticles", Journal of Luminnescence 158 (2015) 181.

[21] Y. Wang, X. Liang, E. Liu, X. Hu \& J. Fan, "Incorporation of lanthanide (Eu3+) ions in $\mathrm{ZnS}$ semiconductor quantum dots with a trapped-dopant model and their photoluminescence spectroscopy study", Nanotechnology 26 (2015) 375601.

[22] G. Colibaba, M. Caraman, I. Evtodiev, S. Evtodiev, E. Goncearenco, D. Nedeoglo \& N. Nedeoglo, "Influence of annealing medium on photoluminescence and optical properties of $\mathrm{ZnSe}: \mathrm{Cr}$ crystals. Journal of Luminescence 145 (2014) 237.

[23] G. M. Lohar, S. K. Shinde, M. C. Rath \& V. J. Fulari, "Structural, optical, photoluminescence, electrochemical, and photoelectrochemical properties of Fe doped ZnSe hexagonal nanorods", Materials Science in Semiconductor Processing 26 (2014) 548.

[24] G. M. Lohar, S. T. Jadhav, M. V. Takale, R. A. Patil, Y. R. Mab, M. C. Rath \& V. J. Fulari, "Photoelectrochemical cell studies of Fe2+ doped ZnSe nanorods using the potentiostatic mode of electrodeposition", Journal of Colloid Interface Science 458 (2015) 136.

[25] E. R. A. Moses, D. S. Mary, C. Sanjeeviraja \& M. Jayachandran, "Growth of $\mathrm{ZnSe}$ thin layers on different substrates and their structural consequences with bath temperature", Physica B 405 (2010) 485.

[26] H. Metina, S. Durmus, S. Erat \& M. Ari, "Characterization of chemically deposited $\mathrm{ZnSe} / \mathrm{SnO}_{2} /$ glass films: influence of annealing in $\mathrm{Ar}$ atmosphere on physical properties", Applied Surface Science 257 (2011) 6474.

[27] J. Tauc, Amorphous and liquid semiconductors, Plenum press, London \& New York (1974).

[28] N. F. Mott \& E. A. Davis, Electronic Processes in Non-Crystalline Materials, 2nd edition Clarendon, Oxford (1979). 